\title{
FONKSIYONÊN HEVBEŞ Û ZINCÎREYA RÛDANÊ DI VEGÊRANA EDEBIYATA KURDÎ YA SOVYETÊ DE
}

\section{Zülküf ERGÜN*}

\section{Kurte}

Ev gotar di mînaka şeş deqên edebî de ku xeta giştî ya vegêrana edebiyata kurdî ya Sovyetê temsîl dikin, hewl dide fonksiyonên hevbeş û zincîreya rûdanê ya vê edebiyatê destnîşan bike. Edebiyata kurdî ya Sovyetê ji ber hin sedemên diyarkirî xwe dispêre fonksiyon û zincîreya rûdanê yên hevbeş. Zincîreya rûdanê ya van berheman ji deh fonksiyon û elementên vegêranê yên mîna zordariya axa û began, zordestiya Roma Reş, rev, xêrxwazî û dostaniya ermeniyan, qenciya rûsan, rizgarkeriya Şoreşa Bolşevîk, astengiya adetên xirab ên berê û dijayetiya wan, bicihkirina bernameya damezirandinê ya sosyalîst, beşdariya Şerê Weteniyê û folklorheziyê pêk tê. Rêzbendî û jimareya van fonksiyonan di vegêrana vê edebiyatê de sê kategoriyên vegêranî derdixe holê. Di kategoriya yekem de rûdan berî Şoreşa Bolşevîk dest pê dikin û rûdanên piştî Şoreşê jî vedigirin. Di vê kategoriyê de kêm zêde hemû fonksiyonên navborî di vegêranê de cih digirin û mebesta wan a sereke berawirdkirina serdema berî Şoreşê û piştî Şoreşê ye. Berhemên vê kategoriyê ji ber ku demeke dirêj vedigirin panaromîk in û di her qonaxekê de rûdan û karekterên nû li berheman tên zêdekirin. Ji ber vê, di van berheman de belawelabûna zûrbûnê, nebûna rûdaneke navendî û qelsiya karekterên sereke wek kêşeyên hunerî derdikevin holê. Di kategoriya duyem de rûdan dîsa berî Şoreşê dest pê dikin bi serketina Şoreşê bi dawî tên. Di vê kategoriyê de vegêran li ser zordestiya serdema feodal û zemînesaziya Şoreşa Bolşevîk zûr dibe. Di kategoriya sêyem de jî berhemên edebî tenê rûdanên piştî Şoreşê vedigirin û zûrbûn li ser bernameya damezirandinê û avakirina nasnameya Sovyetê ye. Di van cure berheman de kêşeya sereke ew e ku girêya rûdanan bi hêsanî tê çareserkirin û mirov hest bi tu milmilaneyê nake.

Bêjeyên Sereke: Fonksiyon, zincîreya rûdanê, fabula, sujet, vegêran, edebiyata kurdî ya Sovyetê.

\section{SOVYET KÜRT EDEBIYATI ANLATISINDA ORTAK FONKSIYONLAR VE OLAY ÖRGÜSÜ}

Öz

$\mathrm{Bu}$ makale Sovyet Kürt edebiyatının ana hattını temsil eden altı edebi metin örneğinde bu edebiyatın ortak fonksiyon ve olay örgüsünü tespit etmeye çalışmaktadır. Sovyet Kürt edebiyatı belirli bazı faktörlerden dolayı ortak fonksiyon ve olay örgüsüne dayanmaktadır. Bundan dolayı bu edebi eserlerin olay

\footnotetext{
Makale Gönderim Tarihi: 07.02.2017, Kabul Tarihi: 30.04.2018

Doi: $10.26791 /$ sarkiat.391307

*Öğr. Grv. Dr. Mardin Artuklu Üniversitesi, Kürt Dili ve Kültürü Anabilim Dalı, zxweshevi@gmail.com, Orcid ID: 0000-0001-8784-5636
} 
örgüsü; ağa ve beylerin istibdadı, Roma Reş'in istibdadı, kaçış, Ermenilerin dostluğu ve hayırhahlığı, Rusların iyiliği, Bolşevik Devrimin kurtarıcılığı, eski kötü adetlerin engelleyiciliği ve buna karşı geliştirilen karşıtlık, sosyalist inşa programı, ulusal savaşa katılım ve folklorseverlik gibi on fonksiyon ve anlatı elementlerinden meydana gelmektedir. Bu edebiyatın anlatısında fonksiyonların siralanması ve sayısı üç farklı anlatı kategorisini ortaya çıkarmaktadır. İlk kategoride olaylar Bolşevik Devrimden önce başlayıp Devrimden sonraki olayları da içermektedir. $\mathrm{Bu}$ kategoride aşağı yukarı adıgeçen bütün fonksiyonlar yer almakdatır ve temel amaç Devrim öncesi ve Devrim sonrası dönemleri karşılaştırmaktır. Bu kategorideki eserler uzun bir zaman dilimine dayanıp sürekli yeni olaylar ve karekterlerle genişledikleri için panaromiktirler. Bundan dolayı bu eserlerde odaklanma sorunu, merkezi bir olayın olmaması ve karekterlerin zayıflığı temel teknik sorunlar olarak ortaya çıkmaktadır. İkinci kategoride olaylar yine Devrimden önce başlayıp Devrimin başarısı ile sonlanmaktadır. Bu kategoride anlatı feodal dönemin istibdadı ve Bolşevik Devrimin hazırlığına odaklanmaktadır. Üçüncü kategoride edebi eserler sadece Devrimden sonraki olayları içerip odaklanmanın merkezinde sosyalist inşa programı ve Sovyet kimliğinin inşası yer almaktadır. Bu eserlerdeki temel sorun da dügüumün kolayca çözülmesi ve çelişki ve gerginliğin zayıflığıdır.

Anahtar Sözcükler: Fonksiyon, olay örgüsü, fabula, sujet, anlatı, Sovyet Kürt edebiyat1.

\title{
COMMON FUNCTION AND PLOT IN THE NARRATION OF SOVIET KURDISH LITERATURE
}

\begin{abstract}
This article deals with establishing the common functions and plot of Soviet Kurdish literature in the example of six literary texts which represent the outline of this literature. Soviet Kurdish literature is based on the common functions and plot because of some certain factors. Therefore the functions and plot of these literary works consist of ten elements of functions and narration such as despotism of agha and landowners, Roma Reş's despotism, escape, friendship and benevolent of Armenian, benevolent of Russians, saviour of Bolshevik Revolution, obstructiveness of the old bad traditions and the opposition of this in turn, social construction programme, involvement in national war, and love of folklore. In this literary narration, the sequence and number of the functions reveal three different narrations. In first category events contain the events before and after Bolshevik Revolution. In this category there are all of the above-mentioned functions and the fundamental aim here is to compare the periods before and after the Revolution. The works in this category are panoramic because of the fact that they are based on the long term and constantly expanded with the new events and new characters. Therefore in these works, dispersion of focus, absent of central event and weakness of characters distinguish as the fundamental technical problems. In the second category the events also start before the Revolution, and result in the success of the Revolution. In this category the narration focuses on the despotism in the feudal period and the preparation of Bolshevik Revolution. In the third category, the literary works consist of only the events after the Revolution and social construction programme and building Soviet identity take place at heart of the focus. The main problem in these works is the unravelling of the climax easily and the weakness of contradiction and tension.
\end{abstract}

Keywords: Function, Plot, Fabula, Subject, Narration, Soviet Kurdish Literature 


\section{Destpêk}

Di pêkhatina berhemeke vegêranî de çendîn regezên girîng hene ku di nav tevahiyeke organîk de hev temam dikin. Motîf yekeyên herî biçûk ên vegêranê pêk tînin ku carinan dadikevin asta hevokekê (Propp, 2011: 17; Tomaşevski, 2010: 252), fonksiyon beşên sereke yên vegêranê ne û fabula jî bê liberçavgirtina guherînên goşenîga û demê rêzkirina hemû rûdanên nav berhemê ye (Onega-Landa, 2002: 17). Li ser vê bingehê zincîreya rûdanê di nav rêzbendiyeke taybet de li ser pevgirêdana kiryar/fonksiyonên fabulayê derdikeve holê. Li gor Boris Tomaşevski ev regezên vegêranê ji helbest û berhemên gernameyî ciyawaztir di roman, çîrok û destanên helbestkî de bi rêya kronolojî û têkiliya sedemtiyê bi hev ve tên girêdan (Tomaşevski, 2010: 251). Forster ji vê pevgirêdana hunerî re plot (Forster, 2001: 128), formalîstên rûsî jî sujet dibêjin û wê ji çîrokê yan jî fabulayê ciya dikin. Lewra rûdanên berhemeke vêkxistî (fîktîf) li gor dema kronolojîk bên rêzkirin jî li ser rêkxistina demê tê lîstin, hin rûdan bi kurtasî, hinek bi dirêjahî tên behskirin, çîrok yan jî fabula di nav plot/sujetê tê rêkxistin (Dervişcemaloğlu, 2014: 20-21) û zincîreya rûdanên berhemên edebî tê pêkanîn.

Mirov dikare bibêje ku cara pêşî Vladimir Propp di xebata xwe ya Morfologiya Skazkiyê de (Teşenasiya Xeberojkan) peywendiya fonksiyon, fabula û zincîreya rûdanê vedikole û di çarçoveya xeberojkên neasayî yên rûsî de hewla derxistina rêzimana vegêranê dide. Li gor Propp ev xeberojkên ku xwe dispêrin sih û yek fonksiyonên hevbeş ji aliyê binyada xwe ve li ser yek tîpî ne û rêzbendiya wan hertim mîna hev e (Propp, 2011: 26). Bêguman ev hevbeşiya xeberojkên neasayî çavkaniya xwe ji bîra hevbeş a anonîm werdigire ku hemû ciyawaziyan vedigerîne ser yekgirtinekê. Her wek vê, edebiyata kurdî ya Sovyetê jî ji ber ku xwe dispêre bîra etnîk a kurdên êzîdî û rêbaza realîzma sosyalîst, di deqên vê edebiyatê de em rastî hevbeşiyên berbiçav ên vegêranê tên ku bi dîtina me ev hevbeşî digihîjin asta form û rêzimaneke yekgirtî ya vegêranê. Ji ber vê, ji aliyê fonksiyon û çêkirina zincîreya rûdanê ve di nav piraniya berhemên edebiyata kurdî ya Sovyetê de hevterîbiyeke aşkera li ber çavan dikeve.

Di vê xebatê de ji bo diyarkirina xeta giştî ya vegêrana edebiyata kurdî ya Sovyetê romana Jiyana Bextewar a Erebê Şemo (1959), Hewarîya Heciyê Cindî (1967), Kurdê Rêwîya Sehîdê Îbo (1979), Dê û Dêmarîya Egîdê Xudo (1986), novellaya Morofề ya Eliyê Evdilrehman (1957) û çîroka Xezalê ya Sîma Semendê (1961) wek nimûne hatine wergirtin. Bêguman ji bilî van berheman jî gelek berhemên edebî hene ku mirov dikare di vê çarçoveyê de binirxîne. Ev roman, novella û çîrok ji bo destnîşankirina sê kategoriyên sereke û deh fonksiyonên hevbeş ên vegêrana edebiyata Kurdî ya Sovyetê hatine hilbijartin û nivîskarên navborî jî di vî warî de kesayetên naskirî yên vê edebiyatê ne. Li ser vê bingehê di van berheman de bi giştî deh fonksiyonên sereke yên vegêrana edebiyata kurdî ya Sovyetê hatine destnîşankirin ku ev fonksiyon hem xwedî taybetiyeke binyadî ne hem ji bi îmajên etnîk û îdeolojîk dagirtî ne. Ev deh fonksiyon ev in: zordariya axa û began, zordestiya Roma Reş, rev, xêrxwazî û dostaniya ermeniyan, qenciya rûsan, rizgarkeriya Şoreşa Bolşevîk, astengiya adetên xirab ên berê û dijayetiya wan, bicihkirina bernameya damezirandinê ya sosyalîst, beşdariya Şerê Weteniyê û folklorhezî.

Bêguman hebûna van deh fonksiyonan nayê wê wateyê ku her deh jî di hemû berheman de tên bikaranîn. Li gor kategoriya wan a demî di hinek berheman de hemû û di hinekên din de jî çendek ji wan tên bikaranîn, lê ya girîng ew e ku ev fonksiyon di hemû deqên edebî de bi heman îmaj û erkê derdikevin pêş. Eger em 
fonksiyona folklorheziyê li derve bihêlin carinan di dema gotarê de rêzbendiya van fonksiyonan biguhere jî bi giștî li gor kronolojiyekê li dû hev rêz dibin û fabula û zincîreya rûdanê ya deqên edebiyata kurdî ya Sovyetê pêk tînin.

\section{Zordariya Axa û Began}

Zordariya axa û began bêtir di wan deqan de derdikeve pêşberî me ku behsa rûdanên berî Şoreşa Bolşevîk dikin. Ev fonksiyon wek kiryara bizwêner a destpêkê di çêkirina girêya rûdanê de roleke sereke dilîze û rê li ber fonksiyonên din vedike. Ji bilî vê rola wê ya binyadî, ev fonksiyon ji ber riwangeha îdeolojiya çînî ya Sovyetê xwedî îmajeke nerênî ye û di deqên edebî de jî hertim wek regezeke serkutker derdikeve pêş.

Di Jiyana Bextewar a Erebê Şemo de kiryara girêçêker a pêşî zordariya Silêman Beg e. Ev kes pişta xwe dide dewleta Romê û ji aliyekî ve ji xelkê bac werdigire ji aliyê din ve dest datîne ser nîvê mîrata kesên mirî û qelenê keçan (Şemo, 2015: 26). Rûdana dawî ya ku milazimê Romê ji Stenbolê tê û Silêman Beg li ser daxwaza wî baceke giran dide ser gundiyan dibe sedem ku eşîreta Sîpkan welatê xwe terk bikin û berê xwe bidin Rûsyayê. Ji bilî vê di romanê de bi çendîn boneyên din behsa zordariya began tê kirin û di her mînakê de beg dest datînin ser ked û namûsa xelkê û dibin sedema kuştin û jinavbirina hinek mirovan. Rûdana Mîrza Beg û Sibhanayê, Mistefa Beg û Îbrahîmê şivan, Meşedî Abas Xan û Teyo Beg çendek ji van in ku her yek ji wan trajediyekê li dû xwe dihêle.

Di çarçoveya vegêrana serpêhatiyên berî Şoreşa Bolşevîk de di Hewarîyê de li ser zimanê Emerîk behsa zordariya Mûrad Axa tê kirin. Li gor Emerîk sala ku eşîreta wan li Rûsyayê bi cih dibe Mûrad Axa baceke zêde dide ser gundiyan. Dema gundî giliya wî bi dewletê dikin rayedarên dewletê piştgiriya Mûrad Axa dikin û di ser de jî arvanên gundiyan di beramberî baca axa de mor dikin. Kesên mîna Emerîk dema ji birçîna morê dişikînin jî lêdan dixwin û bi mişextkirina Sîbîryayê tên tirsandin (Cindî, 2008: 173-175).

Di Kurdê Rêwî de zordariya Hemîd Beg kiryara destpêkê ya romanê ye û girêya rûdanê jî li dor vê fonksiyonê çê dibe. Dema Eliyê şivanê Hemîd Beg dimire ji ber ku di serdema bavê wî de guran pêncî mîhên Hemîd Beg xwarine, Hemîd Beg bê ku heq bidiyê bi Keremê kurê wî yê panzdeh salî şivantî dide kirin. Piştî temamkirina deyn jî heqê wî nade û ji ber ku dil berdaye Zeytûna keça wî Kerem dide kuştin. Jixwe Hemîd Beg di gund de ji kê nexweş be mala wan bi rêya cerdeyan dide talankirin û bi heman awayî mala Zurbe û Hemze jî dide talankirin û wan ji gund derdixe.

Di Morofa Eliyê Evdirehman de jî zordariya began kiryara destpêkê ya bizwêner e. Morof şivanê Xalit Beg e, ji ber ku lingê bilindireke wî dişike Xalit Beg êşkence pê dide kirin û ji bo ku bimire bi rêya xulamên xwe wî davêje Geliyê Qetlê. Di rastiyê de Geliyê Qetlê cihê kuştina mirovên belengaz e û Xalit Beg kê ceza bike wî li wir dide kuştin. Eger Şemoyê şivan û çendekên din Morof li wir nebînin û wî di şikeftekê de veneşêrin heman aqîbet dê bi serê Morof de jî bê. Ji ber vê, dema Morof bi ser xwe de tê ji wî gundî direve.

\section{Zordariya Roma Reş}

Zordestiya Romê herwek fonksiyona zordariya axa û began di deqên edebiyata kurdî ya Sovyetê de fonksiyoneke girêçêker e û dibe sedema rev û koça ji welat. Ji vî aliyî ve mirov dikare bibêje ku li pişt zordariya axa û began jî desthilata Romê heye. Ev zordestî di edebiyata kurdî ya Sovyetê de ew çend karîger û travmatîk e 
dema ku navê Romê derbas bibe yekser rengdêra "reş" pê ve tê zeliqandin û ev fonksiyon heta bibêjî bi îmajeke nerênî tê dagirtin.

Di Jiyana Bextewar de ji zordariya Silêman Beg bêtir bac û zordestiya Romê dibe sedema koç û reva eşîreta Sîpkan ji bo welatê Rûsyayê. Piştî vê rûdanê di maweya Cenga Cîhanê ya Yekem de careke din eskerên Romê dibin sedema rev û koça kurdên Sîpkî. Ji ber vê jî endamên eşîreta Sîpkan kengê behsa Romê bê kirin hertim di bîra wan de bîranînên nerênî zindî dibin û dibêjin: "Xwedê textê Sultan Hemîd wergerîne, wekî wî koka Kurdên belengaz anî, em talan kirin... Xwedê neke em dîsa têkevin destê qaymeqamê Romê, zabitêd wan û mulazimêd wan. Ew zilmkar in" (r. 98).

Di Hewarîyê de li ser zimanê Şewêş bi çîroka "Reşê Qaçtî" kiryara zordestiya Romê tê behskirin. Di vê çîrokê de eskerên Romê êrîşî kurdên Sîpkî dikin û ji bo ku li dijî wan derdikeve postê gurî li Ozmanê Cezo dikin û wî davêjin ber kûçikan. Ji termê Ozman tenê çend tiliyên wî dimînin û wan tiliyan jî bi serê rimekê ve dixin û di nav gundan de digerînin (r. 82). Di Hewarîyê de zordestiya Romê hertim bi dîmenên tirsnak ên êşkenceyê tê berçavkirin. Ji ber vê dema eskerên Romê êrîşî gundê Camûşvanê dikin mezelan dikin nîşangeh, kurê Elî Axa wek pezekî ser jê dikin, dest û lingê Şukrî bi textekî ve mîx dikin û wî dişewitînin (r. 385-386) û şevekê hemû mêrên Camûşvanê dikujin û termên wan dişêlînin.

Di romana Kurdê Rêwî de zordestiya Roma Reş di dawiya romanê de tê behskirin. Ûmnov bi nameyekê hevalên xwe agahdar dike ku dê artêşa Romê êrîşî kurd û ermeniyên wê deverê bike. Ji ber vê di pêşengiya Sûrên û Hemze de gundî ber bi çemê Erezê ve koç dikin û ji zordestiya Romê direvin.

\section{Rev}

Ji her du fonksiyonên jorîn jî tê fêmkirin ku kiryara reva kurdên êzîdî ji welatê xwe ji ber zordestiya Romê û zordariya axa û begên kurdan çê dibe. Ji ber vê, piştî ku behsa zilma Roma Reş û axa û begên kurdan tê kirin wek xeleka sêyem a zincîreya rûdanê behsa revê tê kirin. Loma jî ev her sê fonksiyon di çarçoveya têkiliya sedem û encamê de bi hev ve tên girêdan û wek fonksiyonên pevgirêdayî û bizwêner hertim li dû hev tên rêzkirin.

Di Jiyana Bextewar de du car behsa revê tê kirin. Reva yekem ji ber zordariya Silêman Beg û baca Romê çê dibe. Di vê revê de di navbera kurdên Sîpkî û eskerên Romê de şer derdikeve û di encamê de kuştî û birîndar çê dibin. Reva duyem di maweya Cenga Cîhanê ya Yekem de dîsa ji ber Romê çê dibe û di bin sernavê "Dîsa Rev"ê de tê behskirin. Kiryara revê di romanê de hertim di nav tirs û zehmetiyê de tê berçavkirin û di reva duyem de jî heman tişt rûdidin: "Meriv ku ji dûr ve lê dinêrî; pez, dewar, zar, kulfet tevî hev bûbû. Te digot dewar jî hûsnê Xwedê fam dikir, wekî eskerên padşayê Romê tê û zilmê bi xwe re tîne, wî heywanetî dikir borebor, direvîya" (r. 156). Di vê revê de jî Romê xwe digihîne koçberan, şer derdikeve, koçber xwe li çem diqelibînin û diçin gundê Axbaranê, lê çend roj paşê Romê tê wir û li wir jî dest bi kuştarê dike.

Heciyê Cindî jî di Hewarîyê de di bin sernavê "Dîsa Rev, Dîsa Bez"ê de behsa reva ji Romê dike. Di destpêka Şoreşa Bolşevîk de dema artêşa rûs dişike di nav kurdên wê deverê de tirsa rev û koçê dest pê dike. Vegêr wateya revê ji bo kurdên êzîdî weha şîrove dike: "Rev... Çi qas xebereke zor û zulm e, di nava wê xeberê de çi qas xwîn, derd û kul heye" (r. 372). Ji ber vê, nûçeyeke nerast a hatina Romê jî dibe sedema tirs û reva xelkê ku di encamê de malên wan ji aliyê hin dizan ve tên 
talankirin (r. 373-375). Piştî demekê bi rastî jî eskerên Romê êrîş dikin û kurdên êzîdî ji ber zordestiya wan dest bi revê dikin.

Di dawiya romana Kurdê Rêwî de Ûmnov bi nameyekê ji hevalên xwe yên şoreşgêr re diyar dike ku artêşa Romê ber bi çemê Erezê ketiye tevgerê û ji wan dixwaze ku xelkê agahdar bikin da ku ji wir birevin. Li ser gotina wan gundiyên Qereqoyînê berê xwe didin çemê Erezê û derbasî axa Ermenistanê dibin ku çendek berê ketiye bin hukmê Sovyetê. Bi heman awayî di Morofa Eliyê Evdilrehman de jî li hember zordariya axa û began dema Morof û hevalên wî dibihîzin ku li Rûsyayê Şoreşa Bolşevîk dest pê kiriye û Ermenistan ketiye bin destê Bolşevîkan direvin û xwe li ermeniyan digirin.

\section{Xêrxwazî û Dostaniya Ermeniyan}

Ermenî di vegêrana edebiyata kurdî ya Sovyetê de hertim wek dost û xêrxwazên civaka kurdî tên berçavkirin, lewra kurdên êzîdî jî mîna ermenan ji aliyê desthilata Osmaniyan ve ji war û welatê xwe tên derxistin û ev dibe sedem ku di navbera her du civakan de nêzîkbûnek çê bibe. Di encama vê de kurdên êzîdî di serdema Sovyetê de xwe li ermeniyan digirin û bi arîkariya wan dest bi jiyaneke nû dikin. Ji ber vê çendê karekterên ermenî di berhemên edebî yên kurdî de berî Şoreşê di rizgarkirina kurdan de wek rêber û arîkar derdikevin pêş û piştî Şoreşê jî di pêşvebirin û ronakgeriya kurdên êzîdî de wek kesên zana û ronakbîr rol digêrin. Ev fonksiyon bi nîsbet fonksiyonên pêşî sekna û xwedî roleke kêmtir be jî bi îmajeke erênî dagirtî ye û wek regezeke geşbîniyê di berhemên edebî de cih digire.

Di Jiyana Bextewar de dema milazimê Romê tê gundê kurdan li hember têkiliya baş a kurd û ermenan şaş dibe. Ji ber vê dostaniyê jî dema giregirên eşîreta Sîpkan biryar didin ku koçî Rûsyayê bikin Kîrakosê ermenî rêbertiya wan dike. Bi heman awayî dema Sertîp û malbata xwe ji gundê Axbaranê ji ber Romê direvin xwe li ermeniyên Gola Sevanê digirin. Sertîb dema bi jina xwe re li ser dostanî û arîkariya ermeniyan diaxive diyar dike ku dema şerê wan û Romê çê dibe ermeniyên gundê cîran pişta wan digirin û gava ku ji ber Romê jî direvin Kîrakosê ermenî rêbertiya wan dike. Ji ber vê jî ermeniyan wek "destbirakên" kurdan bi nav dike (r. 175). Di Hewarîya Heciyê Cindî de jî li ser zimanê Emerîk ermenî wek kesên xerîbdost tên nasandin ku deriyê xwe li kurdan vekirine (173).

Di Kurdê Rêwîya Sehîdê Îbo de Sûrênê ermenî wek xêrxwazekî kurdan ji bo ku kesekî xwenda di nav eşîreta Ortila de nîne dixwaze çend kurdan bişîne gundê Zorêyeyê da ku li wir bixwînin. Herweha dema Zurbe ji ber zordariya Hemîd Beg ji gundê xwe derdikeve, mala xwe dibe gundê ermeniyan û ermeniyên dost arîkariya wî dikin. Di romanê de kurd û ermenî wek nas û dostê bav û kalan tên nîşandan ku bi salan dest dane hev û dilê xwe li her hev vekirine (Îbo, 2009: 49). Di Morofê de jî dema Memo û Morof amadekariya revê dikin dixwazin xwe li ermeniyan bigirin û weha bawer dikin ku "cimaeta ermenî ya bira" dê li wan xwedî derkeve (Evdilrehman, 2012: 80). Ji ber vê, berî ku bikevin rê Memo bi hevalên xwe re diaxive û diyar dike ku ermenî xwedî gotina xwe ne, tu carî mirovan nafíroşin, kî xwe bavêje bextê wan wî diparêzin û arîkariya wî dikin (r. 82).

\section{Qenciya Rûsan}

Di vegêrana edebiyata kurdî ya Sovyetê de ji karekterên serbixwe yên rûs bêtir behsa dewleta rûsî tê kirin ku li hember zilm û zordestiya Romê deriyê xwe li kurdan vekiriye û ew ji mirin û qirkirinê rizgar kirine. Ji ber vê, îmaja erênî ya rûsan hertim li hember îmaja nerênî ya Romê tê danîn û ev jî çavkaniya xwe ji serboriya etnîk a kurdên êzîdî werdigire. Di maweya Şoreşa Bolşevîk de ji bo mebesteke 
îdeolojîk li hember rûsên şoreşgêr monarşîzma rûsî bê reşkirin jî ev tu carî karîgerî li ser îmaja erênî ya rûsan nake û qencî û rizgarkeriya rûsan wek fonksiyoneke neguher di vegêrana kurdî ya Sovyetê de cihê xwe digire. Ev fonksiyon jî mîna fonksiyona dostaniya ermeniyan sekna be jî bi îmajeke erênî dagirtî ye û wek regezeke geşbîniyê di berhemên edebî de cih digire.

Di Jiyana Bextewar de dema li ser zimanê Emerîk Romê û rûs tên berawirdkirin li hember xirabiya wan behsa qenciya rûsan tê kirin: "Pak tê bîra min, wekî şîr jî ji malan dibirin, dîsa bipere bû. Lê wexta eskerên Ûris kişiya, çû, zabit û eskerên padşayê Romê hatin, meriv talan dikirin, bi zorê diketin malan.” (r. 37). Ji ber vê jî eşîreta Sîpkan xwe li rûsan digirin û li hember desthilata Romê pesnê rûsan didin: "Mexlûqetê Ûris pak e û birehm e, Xwedê neke em dîsa têkevin destê qaymeqamê Romê, zabitêd wan û mulazimêd wan. Ew zilmkar in" (r. 98). Ji ber vê jî berî Şoreşa Bolşevîk dema eskerên rûs vedikişin tirs li wan çê dibe ku careke din Rom bê, di nav wan de "dîndijminî" çê bike û êzîdî û muslumanan berdin hev.

Di Hewarîyê de jî li hember kiryarên nebaş ên Romê behsa kiryarên qenc ên rûsan tê kirin ku kurdên êzîdî ji zilma wan diparêzin. Dema ku Romê di navbera kurdên êzîdî û musluman de nakokiyê diçîne rûs wan yek milet dibînin û arîkariya wan dikin (r. 100). Di rûdana revandina Gulîzerê û dadgehkirina Egîdê Axa de jî ciyawaziya rûsan derdikeve, lewra dema eşireta Sîpkan û Hesenan li ser vê rûdanê di ber hev re radibin dewleta Rûs dikeve navbera wan û rê nade şerekî çê bibe, lê kurdên êzîdî bi bîr tînin ku di rûdanên weha de dewleta Romê çek didan her du aliyan da ku bêtir hev bikujin (r. 254). Ji ber vê jî dema Gulîzer giliya Egîd dike dewleta Rûsyayê deh sal cezayê mişextiyê li Egîdê Axa dibire û dadperweriya xwe diselmîne.

Îmaja erênî ya rûsan piştî demekê di vegêrana kurdî de vediguhere ser kiryareke minetdariyê. Ji ber vê di Dê û Dêmarîya Egîdê Xudo de dema Efoyê bavê Sîsê naxwaze keça xwe bide Saşayê ku bi eslê xwe rûs e, Reşîd qenciya rûsan a li ser kurdan bi bîr tîne û dibêje: "Hûn ciwan in, nayê bîra we, salên reve-revê ji destê Roma Reş, wextê em ji welatê xwe derketin, kê em xelazkirin, hi? Em çima dûr diçin? Di vî şerî de ûrisa nebûya kê zane ew Hîtlerê merivxur wê çi bihaniya serê me? We ji bîr kiriye?" (Xudo, 1995: 72). Bi vî awayî di mînaka du rûdanên girîng de îmaja parêzvan a rûsan tê dupatkirin û minetdariya li hember rûsan tê derbirîn.

\section{Rizgarkeriya Şoreşa Bolşevîk}

Şoreşa Bolşevîk li hember zordariya axa, beg, maldar û Romê rizgariya yekcarî ya kurdên êzîdî û çîna hejar dabîn dike. Ji ber vê di piraniya berhemên edebî de ev fonksiyon kakila vegêranê pêk tîne û hemû rûdanên pêşî û paşî li dora vê fonksiyona cewherî tên hûnandin. Berî Şoreşa Bolşevîk serdestiya axa, beg û Romê, rev, koçberî û kuştin heye, lê piştî wî wekhevî, dadperwerî, pêşketin, xwendin, avadanî û jiyaneke teze dest pê dike. Ji ber vê Şoreşa Bolşevîk kurdên êzîdî ji zilm û zordariya axa û begên kurdan, qirkirina Romê û paşverûtiya adet û baweriyên pûç rizgar dike.

Di Jiyana Bextewar de dema monarşiya rûsî belav dibe kurdên wê deverê dikevin bin gefa qirkirina Romê û Daşnakan, lê Lenîn û Partiya Bolşevîk wek "xwedîyên kesîban" (r. 126) derdikevin holê û kurdan rizgar dikin. Bi heman awayî Emerîk û Sehîdê kurê wî jî berî Şoreşê li Gurcistanê di nav zehmetiyê de dijîn, lê dema Tiflîs dikeve destê Artêşa Sor mîna hemû kesên belengaz halê wan xweş dibe (r. 208) û bi saya Şoreşa Bolşevîk ji belengaziyê rizgar dibin. 
Di romana Hewarîyê de dema ku kurdên êzîdî dikevin ber zordestiya Romê û bi metirsiya qirkirinê re rûbirû dimînin bi rêya nameya Fêrîk hikumeta Lenîn û Şoreşa Bolşevîk wek rizgarkerê kurdan tê ragihandin. Ev beş di romanê de di bin sernavê "Hewarî"yê de tê veguhestin ku mebest jê gihîştina hewariya rizgarker a Sovyetê ye. Ji ber vê di dawiya romanê de leşkerên Bolşevîk tên Ermenistanê û wan rizgar dikin (r. 400). Jixwe nivîskar di "Paşgotin"a romanê de jî diyar dike ku vê romanê bi boneya çil û pênc saliya avakirina hikumeta Ermenistanê ya Sovyetê nivîsiye ku çil û pênc sal berê gihisştibû hewariya kurdên belengaz.

Di Kurdê Rêwî de dema artêşa Romê êrîşî gundiyên Qereqoyînê dike di bin rêbertiya şoreşgêrên mîna Sûrênê ermenî û Ûmnovê rûs de kurdên êzîdî xwe li Ermenistanê digirin ku çend roj berê ketiye destê hêzên Bolşevîk. Bi heman awayî di Morofa Eliyê Evdilrehman de jî Morof li hember zordariya began peywendî bi hêzên şoreşgêr re datîne, wek rizgarkerê hemû pale û gundiyan pesnê Lenîn dide (73) û di dawiya çîrokê de digel komek mirov berê xwe didin Sovyeta "wetenê aza" û dest bi jiyaneke nû dikin.

Rizgarkeriya Şoreşa Bolşevîk di rûdanên piştî Şoreşê de bêtir di çarçoveya hizrî û çandî de derdikeve pêş ku mirovan ji têgihîştin û çandeke paşketî rizgar dike. Ji ber vê di Xezala Sîma Semendê de li ser zimanê dêya Xezalê tê diyarkirin ku berî Şoreşê keç bi biçûkî dihatin zewicandin û wek pezekê bi qelen dihatin firotin ku di encamê de hinekan xwe dikuşt û hinekên din jî ji ber zordestiya mêran vedigeriyan mala bavê xwe, lê bi raya wê Şoreşê azadî û wekhevî aniye û jin ji wê rewşa xirab rizgar kirine. Xezal jî van gotinên dêya xwe pesend dike û xwe deyndarê "Lenînê mezin û Partiya Komunîst" dizane (Semend, 1996: 9).

\section{Astengiya Adetên Xirab ên Berê û Dijayetiya Wan}

Adetên xirab û têkder hem di rûdanên berî Şoreşê de û hem jî di rûdanên piştî Şoreşê de wek astengî derdikevin pêşiya karekterên erênî û xwedî îmajeke nerênî ne. Adetên xirab di rûdanên berî Şoreşê de wek fonksiyoneke bizwêner dibin sedema çêkirina girêya rûdanê û bi giştî li dû xwe trajediyekê dihêlin, lê piştî Şoreşê ev adet li hember bernameya damezirandinê ya sosyalîst têk diçin û astengiya wan bi hêsanî tê çareserkirin. Ji ber vê ev fonksiyon di rûdanên piştî Şoreşê de xwedî roleke kêmtir e û di çêkirina girêya berhemê de lawaz dimîne.

Di Jiyana Bextewar de baweriya herambûna xwendinê li pêşiya Sehîdê kurê Emerîk dibe asteng, lê dema Artêşa Sor bi ser dikeve li Tiflîsê ji bo her miletî mekteb tên vekirin û Sehîd dest bi xwendinê dike. Di çarçoveya vê hişyariyê de Sehîd herambûna xwendinê baweriyeke pûç dizane û di mînaka kurê Şêx Şemo de herambûna xwendinê wek "giliyeke derew" li qelem dide (r. 207).

Di Hewarîyê de wek adeteke xirab behsa şiletê tê kirin ku zewaca kesekî êzîdî bi kesekî ne êzîdî re qedexe dike. Egîd dema ji bo Sîbîrê tê mişextkirin bi jineke rûs re dizewice û sê zarokên wan çê dibin. Piştî deh salan Egîd digel jin û zarokên xwe tê gund, lê ji ber gunehê şiletê gundî û qewal naçin mala wan (r. 342) û piştî demekê Egîd di bin guvaşa gundiyan û otorîteyên dînî de biryar dide ku bi jineke êzîdî re bizewice. Ev dibe sedem ku Annaya jina wî ya rûs bi zarokên xwe re biçe Sîbîryayê (r. 351) û piştî demeke kurt jî bimire. Bi vî awayî adeteke xirab a berî Şoreşê dibe sedema trajediyeke mirovî û malbateke bextewar ji hev belav dike.

Di Kurdê Rêwî de bijîşkiya gelêrî ya Zînêya keça Pîr Mîrzo wek adeteke xirab tê behskirin ku Zînê bi rîtuelên xerîb û duayan hewla başkirina zarokên biçûk dide. Dema zarok baş nabin Zînê vê bi nezerê ve girê dide û ji dê û bavan dixwaze qurban ser jê bikin. Piştî qurbanê jî eger zarok bimirin Zînê vê carê vê bi emr û qedera 
Xwedê ve girê dide û xwe ji berpirsiyariyê rizgar dike. Herçend Ûsivê biraziyê Şiblî wek kesekî xwenda van kirinên Zînê karekî nerast bide zanîn jî kes jê bawer nake û Zînê van gotinan wek bêrêziya adetên bav û kalan dide zanîn (r. 128).

Di Xezala Sîma Semendê de astengkirina xwendina keçan wek adeteke xirab derdikeve pêş ku Xezal û Karê piştî temamkirina pola dehan rûbirûyê wê dibin. Bavê Karê razî nabe ku keça wî li Erîvanê di nav mêran de bixwîne û wê dide kesekî ku keça wî berê ew nedîtiye. Li hember vê, wek nûnera nişfên piştî Şoreşê astengiya li pêşiya Xezalê zû tê çareserkirin û bi arîkariya dêya wê bavê Xezalê bi xwendina keça xwe razî dibe. Di çîrokê de ji bilî astengkirina xwedina keçan wek adetên xirab behsa qelen û reva keçan jî tê kirin û ev adet jî tên riswakirin û serî nagirin.

Di Dê $\hat{u}$ Dêmarîya Egîtê Xudo de jî em rastî qedexeya zewacê ya êzîdîtiyê tên. Herçend Saşa bi eslê xwe êzîdî nebe jî ji aliyê Karê ve tê xwedîkirin û wek kurdekî êzîdî tê perwerdekirin. Dema mezin dibe û dixwaze bi Sîsê re bizewice êzîdînebûn wek astengî derdikeve pêşiya wî. Karê diçe Sîsê dixwaze, lê bavê Sîsê ji ber şêwra Şêx Sefo vê zewacê pesend nake. Roman ji ber ku li ser rûdanên piştî Şoreşê hatiye avakirin ev astengî bi destpêşxeriya nûnerên nifşên Sovyetê yên mîna Reşîd, Tosin, Semend, Badalyan û Evêlîna Rubênovnaya mamosteya Sîsê û Saşa tê çareserkirin û her du xort digihîjin miradê xwe.

\section{Bicihkirina Bernameya Damezirandinê ya Sosyalîst}

Fonksiyona bicihkirina bernameya damezirandinê ya sosyalîst di rûdanên piştî Şoreşa Bolşevîk de tê behskirin û ji bo nîşandana rewatî û pêşketinxwaziya sîstema sosyalîst a Sovyetê tê bikaranîn. Di van cure berheman de dijberiya nifşên feodal, pêşketinxwazî, xwendin û avadanî mebesta sereke ya deqên edebî ne ku di bicihanîna armancên sîstema Sovyetê de xwedî roleke girîng in. Ji ber vê ev fonksiyon xwedî îmajeke erênî ye û mebesta sereke ya deqên edebî ye.

Di Jiyana Bextewar de bernameya damezirandinê li ser destê Misto û Sehîd tê bicihanîn. Misto di sala 1925an de hewl dide herwekî neteweyên din ên Sovyetê bi saya Partîya Komunîst alfabeyeke latînî ji bo kurdên Sovyetê çê bike. Li aliyê din wek endamê Komîteya Merkezî ya Partiyê hewl dide kesên xwenda û zana di nav kurdan de pêbigihîjin da ku hizrên Lenîn û Partiya Bolşevîk di nav kurdan de belav bikin. Ji bo vê mebestê di 1927an de diçe Moskovayê Stalîn dibîne û di heman salê de ji bo kurdan "Texnîkûma Pêdagogî"yê tê vekirin. Her di vê çarçoveyê de xwendayên wekî Sehîd piştî temamkirina xwendina xwe vedigerin gundê xwe û di pêşvebirina welat de beşdarî dikin. Di sala 1930î de li hemû gundê kurdan kolxoz tên danîn, elektrîk, radyo û rojname tên gundan (r. 243) û hemû ev pêş̧ketin bi Lenîn û Partiya Bolşevîk ve tê girêdan.

Di Hewarîyê de vegêr li ser zimanê apê Moskof qenciya Sovyetê bi bîr tîne û diyar dike ku Sovyet bi rêya sêwîxaneyan hem zarokên sêwî yên kurdan ji mirinê rizgar kirine û hem jî bi rêya "Têxnîkûma Kurdan a Pêdagogiyê" nifşekî xwendewar pêgihandiye (r. 42-43). Di vê çarçoveyê de amaje bi xebatên pêşî yên Lazo tê kirin ku çawa di wan sêwîxaneyan de zarokên kurdan perwerde kirine û ji bo pêşketina çanda kurdî kar kiriye. Herweha hebûna kolxozan û radyoya kurdî dibe sedem ku xalê Şewêş serdema Sovyetê wek "xweş dewran"ekê bi nav bike $($ r. 109, 171) û vê pêşketinê bi bexşîna "mecal û mekan"a Sovyetê ve girê bide.

Eliyê Evdilrehman di dawiya Morofề de cih dide vê fonksiyonê. Piştî serkeftina Şoreşê hêzên şoreşgêr li Ermenistanê pêşî Daşnakan ji nav dibin û demildest li welat qaydeyên kolxoziyê datînin. Ji ber vê mala Memo û kurdên ku ji ber Romê revîne, dikevin nav kolxozê û rojên xwe yên jarî û belengaziyê ji bîr dikin (r. 85). Sîma 
Semend jî di Xezalê de li dor jiyana keçeke kurd dixwaze pêşketina serdema Sovyetê berçav bike ku ev keça gundî tevî rewşa paşketî ya civaka xwe bi saya derfet û azadiya sîstema Sovyetê li Erîvanê bijîş̧kiyê dixwîne û piştî şeş salan dema wek bijîş̧ tê gundê xwe nexweşan ji bin destê kesayetên mîna Şêx Werdayê rizgar dike û di çarçoveya bijîşkiya modern de çareserî ji wan re dibîne (r. 33).

Di Dê û Dêmarîya Egîdê Xudo de gundê Mêrgesorê, ku di navenda rûdanên romanê de ye, xwedî kolxoz, xwendingeh û dîspanserê ye. Di maweya Şerê Weteniyê de li gund ji bo zarokên bê dê û bav sêwîxaneyek tê vekirin û wek mînakeke bicihbûna bernameya damezirandinê keçeke mîna Karê di wî gundî de di sêwîxaneyê de dixebite. Piştî Şerê Weteniyê rewşa gund baştir dibe, hikumet dezgehên curbicur û xaniyên nû çê dike. Ev nîşan dide ku di Dê $\hat{u}$ Dêmarîyê de jî serdema piştî Şoreşa Bolşevîk û bernameya damezirandinê ya Sovyetê wek fonksiyoneke erênî cihê xwe girtiye.

\section{Beşdariya "Şerê Wetaniyê"}

Cenga Cîhanê ya Duyem di berhemên edebiyata kurdî ya Sovyetê de wek "Şerê Wetaniyê" tê binavkirin ku di wê demê de ji bo tevahiya edebiyata Sovyetê mijareke populer e. Ev mijar di vegêrana kurdî de wek fonksiyona çêkirina nasnameya Sovyetê û dijayetiya hêzên faşîst tê bikaranîn û bi nîsbet fonksiyonên din kêmtir tê berçavkirin.

Di Jiyana Bextewer de di bin sernavê "Di Şerê Wetaniyê Ê Mezin De" behsa vê fonksiyonê tê kirin. Di sala 1941ê dema Komîteya Merkezî ya Partîya Komunîst a Ermenîstanê ji bo xwendina “ulmê Marxîzm û Lenînîzmê” Sehîd dişîne Moskovayê Hîtler êrîşî Sovyetê dike û Şerê Wetanîyê dest pê dike. Wê rojê Sehîd digel xortên komunîst diçe eniya şer, li Bêlorûsyayê wek albay serkeftinên mezin bi dest dixe û wek qehremanekî li ser navê serokatiya Sovyetê nîşana "Mêrxasê Tifaqa Sovyetîyê" pê tê bexşîn (r. 279).

Di Dê $\hat{u}$ Dêmarîya Egîtê Xudo de di navenda rûdana romanê de kiryara Şerê Wetaniyê heye. Ji ber vê di serê romanê de jineke rûs dibe mêvanê Karê û ev jin ji bo parastina welat û tolhildana hezkiriyên xwe pitikê xwe yê di pêçekê de li cem Karê dihêle û beşdarî şer dibe (r. 10). Ji bilî vê, Cemalê dergistiyê Karê jî ji bo parastina welat beşdarî şer dibe û piştî demekê nûçeya mirina wî tê. Ji vir û şûn de Karê kurê Evdokyaya rûs wek kurê xwe mezin dike û piştî çend salan Evdokya bi rêya nameyekê jê re diyar dike ku navê Cemalê dergistiyê wê jî mîna mêrê wê yê berê di goristana Ûkraynayê de dîtiye û behsa qehremaniya kurdan dike di wî şerî de (r. 61). Di encamê de Karêya kurd û Evdokyaya rûs di çarçoveya nasnameya hevbeş a Sovyetê de li ser dayîkbûna Saşa digihîjin hev û roman bi vê peyamê bi dawî dibe.

\section{Folklorhezî}

Folklorhezî yek ji taybetiyên hevbeş ên edebiyata kurdî ya Sovyetê ye ku bi îmajeke erênî di vegêrana vê edebiyatê de cihê xwe digire. Ji ber vê li ser zimanê vegêr û karekterên ciyawaz gelek caran gotinên pêşiyan û stranên gelêrî tên veguhestin, behsa çîrok û destanên gelêrî tê kirin û rîtuelên ciyawaz ên folklorîk tên berçavkirin. Bi vî awayî folklor di çêkirina cîhana vêkxistî de dibe keresteyeke vegêranê û berhemên edebî jî dibin qada vejandina mîrata folklorîk. Ev elementa vegêranî wek fonksiyoneke azad û serbest di pevgirêdana rûdanên berheman de roleke çalak negire ser xwe jî bi îmaja xwe ya erênî gelek caran tê dubarekirin.

Erebê Şemo di Jiyana Bextewar de di bin sernavê "Bindarûk"ê de cih dide rîtuela folklorîk a bindarûkê ku keç û xort tên bal hev, stranên gelêrî dibêjin û hev dinasin. 
Ji billî vê di romanê de di mînaka daweta malbata Resûl Axa û Evdila Beg de rîtuelên dawetên kurdewarî yên mîna şabaş, cirîd, rovî, amadekirina dara zava, lîstika Kose û gelî, qaydeyên romanî, şeranî û gulênarî yên sazbendan, pêşkêşiya cihêzan, pêşkêşiya derxistina bûkê, pêşkêşiya şivan, anîna balîfa bûkê, şikandina tebaxekê ji aliyê bûkê ve bi hûrdekarî tên behskirin (r. 64-72).

Heciyê Cindî wek folklornasekî pispor, ji her kesî bêtir romana xwe bi elementên folklorîk dadigire û di Hewarîyê de gelek gotinên pêşiyan, kilam, beyt, serhatî, lawijok, meselok û rîtuelên folklorîk vediguhêze. Ev element carinan ji bo derbirîna xweşiyekê, carinan ji bo xem û dûrketinekê û carinan jî ji bo berhevkirina mîrata folklorîk tên veguhestin. Ji ber vê di romanê de amaje bi kilamên Xecê û Siyabend (r. 44), Evdalê Zeynikê (r. 56), Her Çar Malên Newalê (r. 67), kilameke bênav li ser zimanê Elî Axa (r. 209), kilama Zerîdomamê (r. 98), beyta Mîrze Axa ya dengbêj Şero (r. 69-70), kilama li ser kuştina Ozmanê Cezo, kilama li ser kuştina Gevezê (r. 245-247,250), lawijokên li ser mişextkirina Egîdê Axa (r. 294, 305), kilameke bênav li ser zimanê jinekê (r. 114), helbesteke kurt a gelêrî li ser zozanan (r. 268), kilama şivanekî xort (r. 270), beşek ji serhatiya Eliyê Xwarziya (r. 291), kilameke gelêrî li ser zimanê jinekê (r. 317), kilama Rêza Gundan ya Xudoyê Emer (r. 176-177) û rîtuelên Kosegeldî, dolîdang û Xidirnebî (r. 161-162) tê kirin û vegêrana romanê bi fonksiyonên folklorîk tê xemilandin.

Di Kurdê Rêwî de gelek caran li ser zimanê vegêr û karekteran em rastî gotin û îdyûmên gelêrî yên weha tên: "De zanibe, kî berx e, kî beran e" (r. 18), "zor da zimanê sor" (r. 57), "nanê xwe genimî dikir" (r. 80), "hûkî kiribû mûkî" (r. 111), "em îro penêr in, tu kêr, em pêxas in, tu soldirû" (r. 116), "mala mêra xirab nabe, mala zêra xirab dibe" (r. 134), "lingê pêxasa timê ber derê soldirûya ne" (r. 142). Ji bilî vê di çêkirina karektera Zînê û Pîr Mîrzoyê bavê wê de jî sûd ji folklorê tê wergirtin û bi rêya wan amaje bi Beko Ewan û Zîna keça wî tê kirin. Dema Zînê û Pîr Mîrzo dikevin navbera evîna Kerem û Zeytûnê li ser zimanê Zeytûnê weha tê gotin: "Zînê tu û Mîrzoyê bavê xwe va çi ji ruhê min dixazin, hûn çima mîna dirya orta Memê û Zînê nahêlin miraz biqedin" (r. 104). Herweha di romanê de çendîn caran kilam tên veguhesitin. Dema gundî diçin zozanên çiyayê Sînekê dengê kilama "Kûra çayê, topê Qersê..." (r. 27) li her derî olan dide, gava Kerem derbiharê pez tîne gund kilama "Van baxa: Heta baxa, / Leylanê ha Leylanê" (r. 138) dibêje û herkesî bi dengê xwe mest dike, herî dawî wexta Kerem tê kuştin Perîşana dêya wî kilamekê davêje ser kurê xwe û ev kilama ku bi gotinên "Kerem lao, Kerem lao" dest pê dike di romanê de tê veguhestin (r. 192-193).

Eliyê Evdilrehman jî di Morofề de girîngiyeke mezin dide elementên folklorîk. Lehengê çîrokê Morof dengbêj e û gelek kilamên siwaran, kilamên bengîtiyê, kilamên keçikan, kilamên govendê, beytên Xanî û Feqî, meqamê Siyabendo û Xecêzerê dizane (r. 34). Ji ber vê hunera xwe di dîwana Selîm Beg de dibe dengbêjê wî yê taybetî. Ji Selîm Beg re kilamên Siyabendê Silîvê, Evdalê Zeynikê, Şerê Girîdaxê, Axao, Ezê li Eleganê û Filîtê Quto dibêje (r. 37-38), lê dema Selîm Beg jê dixwaze li ser wî, êla wî û mêrxasên wî kilaman derxe Morof naxwaze hunera xwe bixe bin xizmeta feodalan û diyar dike ku ew wî bi dar ve bikin jî nikare bi kilamên xwe pesnê xelqê bide (r. 44) û bi van gotinên xwe îmaja erênî ya folklorê diparêze.

Sîma Semend di destpêka çîroka Xezalê de dema dîmena bihara Elegezê tîne ber çavan di nav wê tabloya ciwan de behsa dengê stranên keç û xortan dike (r. 5), herweha di çîrokê de dema keç û xortên kolxozvan êvarê vedigerin malên xwe bi hev re kilaman dibêjin (r. 8). Ji bilî kilaman di çîrokê de li ser zimanê Surmê derbarê 
qelen de meselokeke pêşiyan tê veguhestin û di daweta Ahmo û Xezalê de jî lîstika sêpê û hin rîtuelên dawetê tên berçavkirin (r. 39).

Egîdê Xudo jî mîna nivîskarên berî xwe di romana xwe de cih dide gelek gotinên pêşiyan: "gotina pêşiyên me ji bîr meke, siba xweş di sibê de xweş e" (r. 37), "Ev gotina xelkê Kurd, wekî şêr şêr e, çi jin e çi mêr e" (r. 40), "çawa mezinan gotiye pêl tên pêlan winda dikin" (r. 40), "mûkî têkin hûkî" (r. 81), "Bûke li hespê ye, hevsarî li Mistê ye kes nizane qismetê kê ye" (r. 82). Ji bilî van gotinan di şina Ûsiv de jinên dengbêj li ser mirina Ûsiv kilaman dibêjin û beşek ji kilama Karê ya li ser mirina Ûsiv ku bi "Heylo wayê, heylo wayê" dest dike di romanê de tê veguhestin (r. 48). Herweha dema Sîsê tê nasandin li ser zimanê vegêr tê diyarkirin ku Sîsêya dengxweş gelek kilamên mêranî û evîntiyê dizane û carinan piştî dersan ji hevalên xwe re distre (r. 70).

\section{Encam}

Di encamê de ev deh fonksiyon tîpolojiya sereke ya vegêrana edebiyata kurdî ya Sovyetê derdixin ku bi ser sê kategoriyên sereke yên vegêranê de dikarin bên dabeşkirin. Di kategoriya yekem de rûdanên berhemên edebî berî Şoreşa Bolşevîk dest pê dikin û rûdanên piştî Şoreşê jî vedigirin. Di van cure berheman de kêm zêde hemû fonksiyonên navborî di vegêranê de cih digirin û mebesta wan a sereke berawirdkirina serdema berî Şoreşê û piştî Şoreşê ye. Di vê xebatê de Jiyana Bextewara Erebê Şemo û Hewarîya Heciyê Cindî vê kategoriyê temsîl dikin. Loma jî di Jiyana Bextewar de her deh fonksiyon û di Hewarîyê de jî neh fonksiyon cih digirin. Di vê kategoriyê de zordariya axa û begên kurdan û zordestiya Roma Reş wek kiryarên bizwêner, kiryara revê encam didin û girêya rûdanê pêk tînin. Di vekirina vê girêyê de ermen û rûsên dost wek fonksiyonên arîkar derdikevin holê û herî dawî fonksiyona Şoreşa Bolşevîk girêyê vedike. Di rûdanên piştî Şoreşê de bi hûrgulî behsa fonksiyonên bernameya damezirandinê tê kirin, carinan adetên xirab ên berê û Şerê Wetaniyê wek fonksiyonên astengçêker derkevin holê jî di encamê de bernameya damezirandinê bi ser dikeve û ev kêşe bi awayekî serkeftiyane tên çareserkirin. Berhemên vê kategoriyê ji ber ku demeke dirêj vedigirin panaromîk in û di her qonaxekê de rûdan û karekterên nû li berheman tên zêdekirin. Ji ber vê, di van berheman de belawelabûna zûrbûnê (focus), nebûna rûdaneke navendî û qelsiya karekterên sereke wek kêşeyên hunerî derdikevin holê.

Di kategoriya duyem de rûdan dîsa berî Şoreșê dest pê dikin û bi gihîştina kurdên êzîdî ji bo Sovyetê yan jî bi serketina Şoreşa Bolşevîk bi dawî dibin. Di van cure berheman de ji ber maweya diyarkirî ya rûdanê fonksiyonên bicihkirina bernameya damezirandinê û Şerê Wetaniyê nayên behskirin û vegêran li ser zordestiya serdema feodal û zemînesaziya Şoreşa Bolşevîk zûr dibe. Kurdê Rêwîya Sehîdê Îbo û Morofa Eliyê Evdilrehman vê kategoriyê temsîl dikin. Rêzbendiya fonksiyonan di vê kategoriyê de jî herwek kategoriya pêşî ye, lê di vê kategoriyê de herwekî amaje pê hat kirin fonksiyonên piştî Şoreşa Bolşevîk cih nagirin.

Di kategoriya sêyem de berhemên edebî tenê rûdanên piştî Şoreşê vedigirin û zûrbûn li ser bernameya damezirandinê û avakirina nasnameya Sovyetê ye. Di van cure berheman de ji ber sînordariya dema rûdanan bi nîsbet kategoriyên din fonksiyonên navborî kêmtir tên bikaranîn. Di vê xebatê de Xezala Sîma Semendê û Dê $\hat{u}$ Dêmarîya Egîdê Xudo vê kategoriyê temsîl dikin. Di van cure berheman de bernameya damezirandinê ya sosyalîst di navendê de ye, li hember vê, fonksiyona adetên xirab ên berê wek asteng derkeve pêş jî di çarçoveya geşbîniya rêbaza realîzma sosyalîst de ev kêşe bi hêsanî tê çareserkirin. Ev dibe sedem ku di van berheman de girêya rûdanê lawaz be yan jî carinan qet nebe. Di berhemên navborî 
de girêya ku li ser navê adetên berê tê çêkirin ew çend zû û hêsa tê çareserkirin ku xwendevan hema bibêje hest bi tu milmilaneyekê nake. Ji ber vê ye ku kêşeya xwendina Xezalê di çîroka Xezalê ya Sîma Semendê de bi axaftineke dêya wê û kêşeya zewaca Saşa û Sîsê jî di Dê û Dêmarîya Egîdê Xudo de bi navberkariya Reşîd, Badalyan û Evêlînayê bê çêbûna astengiyeke mezin tê çareserkirin.

Tevî hebûna hin awarteyan di her sê kategoriyan de jî rêzbendiya fonksiyonên navborî û rêkxistina zincîreya rûdanan li gor kronojiyê tê sazkirin ku Mîran Celal Mihemed ji vê re dibêje "binyatî şwênkewte" ku yek ji binyadên rêkxistina rûdanên berhemên vêkxistî ye. Li gor wî ev binyad bêtir di wan berheman de tê dîtin ku armanca wan tomarkirin û zindîhiştina rûdanên raborî ne (Mihemed, 2009: 67). Ev pênase jî gelek li deqên edebiyata kurdî ya Sovyetê tê ku nivîskarên wê dixwazin serborî û trajediya kurdên êzîdî bi rêya berhemên edebî tomar bikin û wek bîra kolektîf a travmatîk biparêzin. Ev jî dibe sedem ku zincîreya dîrokî û mantiqî ya rûdanan bê parastin û neyê guhertin. Di Jiyana Bextewar de carinan bi tevîkirina hin çîrokan di vegêrana rûdana romanê de dabirîn çê bibe jî rêzbendiya rûdanan qet naguhere. Herweha di Hewarîyê de vegêr di para yekem de li ser zimanê Moskov û Şewêş di navbera rewşa niha û borî de berawirdiyekê çê bike jî di para duyem a romanê de careke din vedigere ser rêzbendiya rast a vegêranê ku ji berî Şoreşê dest pê dike û heta ragihandina Şoreşa Bolşevîk tê. Jixwe beşa yekem a romanê ji bilî amajeyeke biçûk ku çend caran behsa Fêrîk û Nûrê tê kirin tu peywendiyeke wê ya organîk bi beşa duyem re jî nîne û di şêwaza roportajekê de hatiye nivîsîn. Lê di berhemên din de bê tu îstîsnayekê rûdan li ser xeteke rast tên vegêran û kronolojî nayê xirabkirin. Paşdebirin (flashback) û pêşdebirina (flashforward) ku kêm caran di van berheman de tê dîtin jî ne di asta beşên serbixwe û rûdanên sereke de ne, belkî di nav axaftinên karekteran de wek bîrxistin û pêşbîniyekê derdikeve pêş û ev jî bi tu awayî rêzbendiya rûdanan xirab nake.

Herî dawî mirov dikare bibêje ku hevbeşî û hevterîbiya fonksiyonên vegêrana edebiyata kurdî ya Sovyetê cure anonîmiyekê bi xwe re tîne û rê li ber şêwaza şexsî digire. Çawa ku di serî de jî hat diyarkirin ev anonîmî xwe dispêre îdeolojiya zal a Sovyetê û bîra etnîk a kurdên êzîdî. Jixwe ev nebûna ev qas berhem li ser fonksiyonên hevbeş nedihat avakirin û ji aliyê binyadê ve nêzî xeberojk û romansên Serdema Navîn nedibûn. Bêguman anonîmiya van berheman rêzimaneke hevbeş a vegêranê encam bide jî ji aliyê hunerî ve dibe sedema qelsiyekê. Lewra mîna hemû waran di warê edebiyatê de jî hizir û xeyalên kolektîf gelek caran ciyawaziya kesî ji holê radikin û di edebiyatê de rê li ber îmajên hevpar vedikin. Ji ber dubarekirina îmajên hevpar jî reseniya edebî ji holê radibe û piştî demekê xwendevanên xwe dikerixîne. Edebiyata kurdî ya Sovyetê jî bi van fonksiyonên xwe yên hevbeş dibe deravêteya bîreke kolektîf û rê li ber îmajên takekesî û şêwazên şexsî digire. Ev jî dibe sedema vegêraneke anonîm ku tê de mirov hest bi şêwaza şexsî nake.

\section{Çavkanî}

CINDÎ, Heciyê (2008). Hewarî (Tîpguhêzî, P. Alîmûradî). Diyarbakır: Lîs.

DERVIŞCEMALOĞLU, Bahar (2014). Anlatıbilime Giriş. İstanbul: Dergah Yayınları.

EVDILREHMAN, Eliyê (2012). Morof (Tîpguhêzî, M. Têmûr-D. Têmûr). Diyarbakır: Lîs.

FORSTER, E. M. (2001). Roman Sanatı (Wer. Ü. Aytür). İstanbul: Adam Yayınları. 
ÎBO, Sihîdê (2009). Kurdê Rêwî (Tîpguhêzî, X. Omerxalî). İstanbul: Avesta.

MIHEMED, Mîran Celal (2009). Binyatî Rûdaw le Romanî Kurdîy Başûrî Kurdistan da. Silêmanî: Mellbendî Kurdolocî.

ONEGA, Susana-LANDA, José Angel Garcia (2002). Anlatıbilime Giriş (Y. Salman-D. Hakyemez, Wer.). İstanbul: Adam Yayınları.

PROPP, V. (2011). Masalın Biçimbilimi (Wer. M. Rifat-S. Rifat). İstanbul: Türkiye İş Bankası Kültür Yayınları.

SEMEND, Sîma (1996). Xezal (Tîpguhêzî, Ş. Kaya). Stockholm: Weşanên Nûdem. ŞEMO, Erebê (2015). Jiyana Bextewar. Diyarbakır: Lîs.

TOMAŞEVSKİ, Boris (2010). “Tema Örgüsü” Yazın Kuramı (T. Todorov, Ed.) (M. Rifat-S. Rifat, Wer.) İstanbul: Yapı Kredi Yayınları. r. 247-287.

XUDO, Egitê (1995). Dê û Dêmarî (Tîpguhêzî, N. Kutlay). Stockholm: Weşanên Nûdem. 